\title{
Los infográficos periodísticos como género informativo
}

\author{
Daniel García GonzÁLEZ \\ Universidad del País Vasco \\ daniel.garcia@ehu.es
}

\section{Resumen:}

Desde su eclosión en los años 90 hasta la actualidad los gráficos estadísticos, mapas, diagramas y resto de infográficos se han convertido en un género informativo asentado en la prensa mundial. El presente artículo, estrictamente ceñido a la infografía periodística, desgrana cuáles son las partes que los forman y se apunta a una posible clasificación metodológica. Se analizan las diferencias entre los estáticos, diseñados para medios impresos, y aquellos otros que presentan algún tipo de interactividad con el usuario.

Palabras clave: Infografía; infográficos; generos; prensa; periodismo.

\section{Newspaper infographics as an informative genre in the media}

\begin{abstract}
:
From their eclosion during the 1990s until now, statistical graphics, maps, diagrams and many other newspaper infographics have became a new informative genre in the media all around the world. This paper -which is strictly oriented to social media infographics- analyzes those minimal units in which graphics can be divided and explores a possible classification for methdological purposes. Differences between static infographics -those designed to read be in printed media- and interactive ones are considered too.
\end{abstract}

Key Words: Infographics; graphics; genres; media; journalism.

\section{Referencia normalizada:}

García González, D. (2014): Los infográficos periodísticos como género informativo. Historia y Comunicación Social. Vol. 19. Núm. Especial Febrero. Págs. 93-106.

Sumario: 1. Introducción. 2. Metodología. 3. Los infográficos periodísticos. 3.1. Utilizados desde siempre en prensa. 3.1.1.Mapas, croquis, planos y localizadores. 3.1.2. Estadísticos. 3.1.3. Mapas estadísticos. 3.1.4. Organigramas. 3.1.5. Diagramas. 3.1.6. Multigráficos o 'megagráficos'. 3.2. Diferencia con la ilustración. 3.3. El 'boom' de la infografía de prensa. 3.4. Partes del infográfico. 3.4.1. Titular y encabezados. 3.4.2. Orden de lectura. 3.4.3. Elemento gráfico principal. 3.4.4. La red o 'malla' 3.5. La estaticidad. 3.6. Los gráficos audiovisuales. 3.6.1. Lectura unidireccional. 3.6.2. Dependencia de la duración. 3.6.3. Lectura continua y por tanto parcial. 3.7. El gráfico interactivo. 3.7.1. Es multidireccional. 3.7.2. Es independiente respecto del factor tiempo. 3.7.3. Da una visión de conjunto o primera lectura general. 4. Conclusiones. 


\section{Introducción}

El término 'infografía' tiene en castellano dos grupos de acepciones totalmente diferenciadas. Aunque tradicionalmente han sido muy variados los significados otorgados al vocablo, la mayoría de ellos se articulan en los siguientes dos grandes grupos atendiendo a sendos orígenes etimológicos principales atribuidos al vocablo (CAIRO, 2008: 21). Por un lado, si entendemos la infografía como la unión de informática más grafía denominaremos de esa forma a aquellas imágenes que han sido producidas mediante métodos computerizados, como reproducciones tridimensionales de planos, creación de animaciones por ordenador, etc. Éste es el uso más habitual del término 'infografía' en ámbitos de ingeniería, diseño profesional, informática, arquitectura, etc.

$\mathrm{Si}$, por el contrario, entendemos el término infografía como la unión de información y grafía nos acercaremos más al sentido en el que la utilizamos habitualmente en el mundo del Periodismo. Es decir; aquella técnica que busca transmitir una información mediante la utilización de recursos gráficos de cualquier tipo, como dibujos, mapas, organigramas, etc (COLLE, 1998: 2). Por ejemplo, el infográfico que en 1869 creó el afamado ingeniero francés Charles Joseph Minard mediante técnicas exclusivamente manuales.

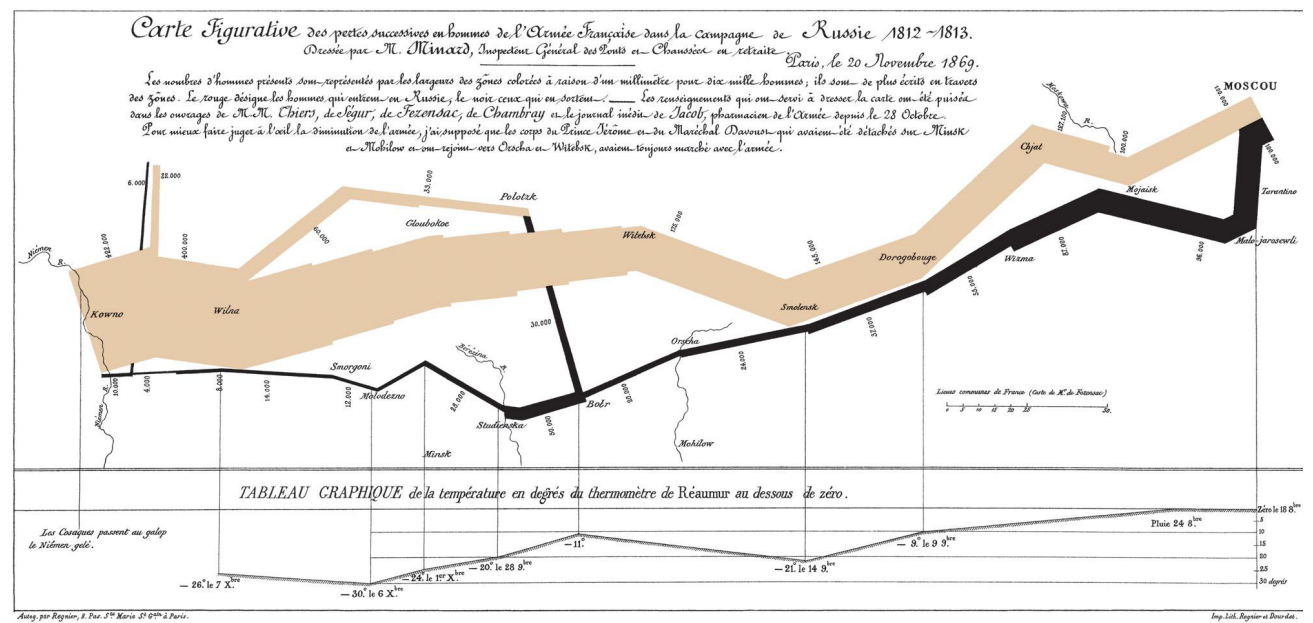

Fuente: TUFTE (2001), pág. 40.

En él se describe muy plásticamente la desastrosa campaña militar de Napoleón contra Rusia entre 1812 y 1813. El grosor de la línea principal equivale al número de soldados en cada momento. El progresivo adelgazamiento de la franja naranja en su avance hacia Moscú da idea de la reducción del tamaño del ejército francés como consecuencia de la guerra. La línea negra indica la vuelta hacia tierras galas. Como se ve, sólo unos pocos lograron retornar con vida. Este impresionante documento nos da información de tres clases. Por un lado, de tipo cuantitativo, ya que muestra 
la evolución comparada del número de soldados a lo largo del tiempo. Por otro, de tipo geográfico, ya que los rótulos repartidos a lo largo del gráfico indican de forma aproximada las ciudades y las zonas de Europa por las que pasó el ejército. Además, en tercer lugar, muestra de forma contextualizada las bajas temperaturas sufridas en cada momento durante la campaña, gracias a la fiebre inferior.

En el ámbito periodístico es habitual denominar infografía tanto a la actividad de creación de esas imágenes como a los propios gráficos en sí. A lo largo de este artículo denominaremos infográficos a los primeros y reservaremos el concepto infografía para referirnos a la actividad profesional dirigida a la concepción y elaboración de aquéllos ${ }^{1}$.

\section{Metodología}

El presente artículo es fruto de una investigación más amplia llevada a cabo por el autor en el marco de la realización de su tesis doctoral sobre la infografía en la prensa española, defendida bajo el título: 'La infografía periodística en España: el caso de El Correo Español-El Pueblo Vasco'. Para su realización se examinaron sistemáticamente los infográficos publicados a lo largo del siglo pasado por este periódico bilbaíno y se revisó la bibliografía referida a este tema, principalmente de origen anglosajón, ya que actualmente todavía son escasas las obras que tocan este género informativo en nuestro idioma. En este trabajo se han condensado aquellas conclusiones que hacen referencia exclusivamente a las partes que componen los gráficos, su clasificación y principales diferencias entre aquéllos estáticos y los interactivos.

\section{Los infográficos periodísticos}

\subsection{Utilizados desde siempre en prensa}

La razón principal por la que desde su nacimiento los periódicos han recurrido a la utilización de infográficos ${ }^{2}$ es porque determinados tipos de información se transmiten mucho más rápida y eficazmente si son mostradas que si son contadas exclusivamente con palabras. El lema de la infografía periodística es 'Show, don't tell' / 'No lo cuentes; muéstralo'. Y es que muchos de los contenidos informativos de los medios de comunicación que pueden ser rápidamente visualizados por el lector en un pequeño infográfico serían imposibles de transmitir mediante sólo palabras o, de intentarlo, conllevarían un enorme esfuerzo de lectura. Podemos ver ejemplos evidentes de todo ello en los tipos de infográficos más utilizados. 


\subsubsection{Mapas, croquis, planos y localizadores}

Los mapas son representaciones simplificadas de una realidad geofísica que, utilizados en los medios de comunicación, nos sirven a los periodistas tanto para ubicar unos determinados acontecimientos como para resumir sobre ellos lo esencial de aquel relato periodístico al que acompañan.

A diferencia del mapa de tipo cartográfico, el infográfico parte necesariamente de un área o zona geográfica conocida por su lector tipo -en este caso, el subcontinente indio- para, a continuación, ubicar en ella la información nueva que es objeto de la noticia - la ampliación sobre la frontera de la región de Cachemira- o destacar los aspectos de especial relevancia, como en este caso la ciudad de Gilgit. LESTER denomina a éstos mapas no estadísticos (2006: 190) y diferencia localizadores de explicadores según predomine una función o la otra.

Gráficos estadísticos

\subsubsection{Estadísticos}

Los gráficos estadísticos permiten transmitir la información cuantitativa de forma mucho más eficiente que con su mera plasmación numérica, ya que permiten realizar comparaciones entre cantidades así como visualizar su evolución en el tiempo. Los más utilizados son:

- Las evoluciones o fiebres, que reflejan los cambios de un determinado valor a lo largo del tiempo.

- Por su parte, las barras son el gráfico más adecuado para comparar cantidades entre sí o en diferentes momentos temporales.

Aunque a primera vista nos puedan recordar a las fiebres, a diferencia de aquéllas, en el caso de las barras los valores referidos sí serían acumulables entre sí y por tanto, llegado el caso, apilables en altura. Así, según la naturaleza de los datos, lo correcto será compararlos mediante un tipo de gráfico u otro (ABREU SOJO, 2000a: 96).

- Los círculos o tartas son el tipo de gráfico más utilizado cuando lo que buscamos es reflejar la proporción de unos determinados valores con el total o suma de todos ellos. Una variante de los círculos son los hemiciclos, usados habitualmente para la plasmación de resultados electorales.

- Finalmente, las tablas de datos facilitan la lectura de cifras o datos al categorizarlos y plasmarlos de forma gráficamente ordenada (LESTER, 2006: 189). ${ }^{3}$ 


\subsubsection{Mapas estadísticos}

Éstos aúnan la rápida legibilidad de los mapas y otros elementos icónicos con los datos numéricos que queramos transmitir. En el siguiente ejemplo, queda clara la tendencia de voto hacia cada partido político según la geográfica, pero no tiene en cuenta la densidad poblacional de cada circunscripción electoral en Reino Unido.

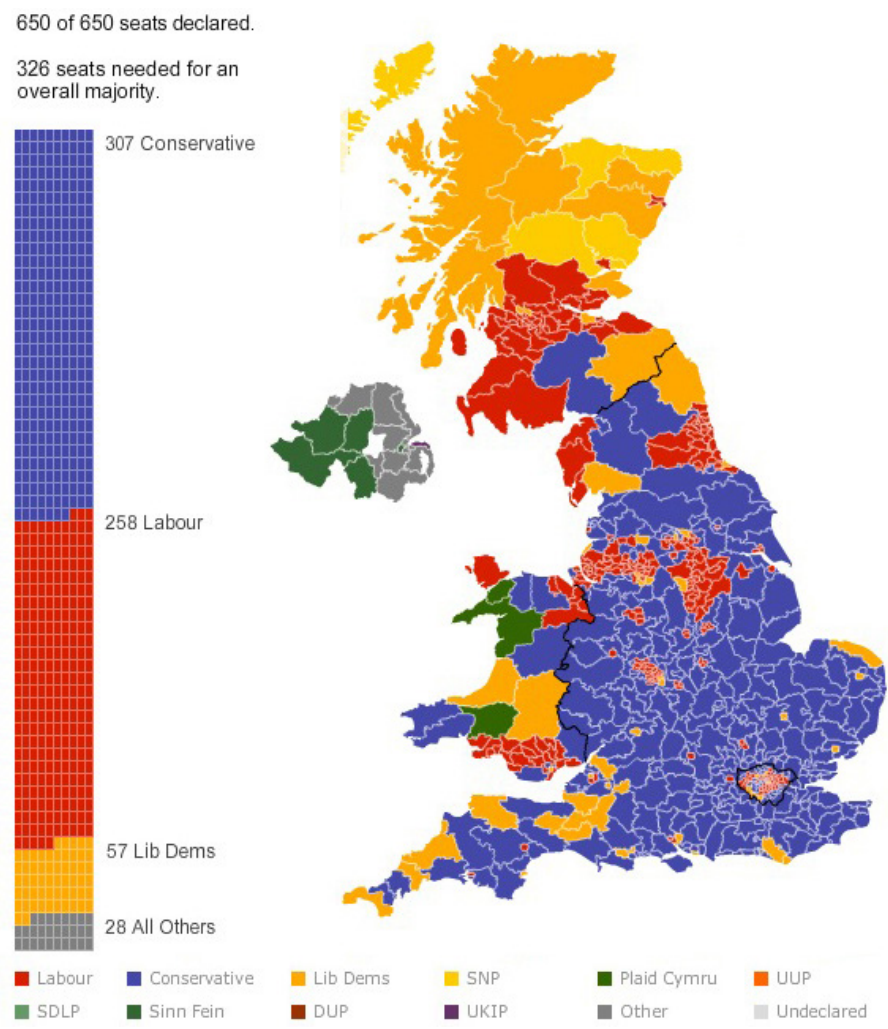

Fuente: news.bbc.co.uk (octubre de 2011)

En esta variante del mismo infográfico, por el contrario, se muestran esos mismos datos pero atendiendo al peso relativo de la población. Nótese el aumento de tamaño relativo de Londres y la disminución en el área ocupada por las Tierras Altas de Escocia, mucho menos densamente pobladas. 


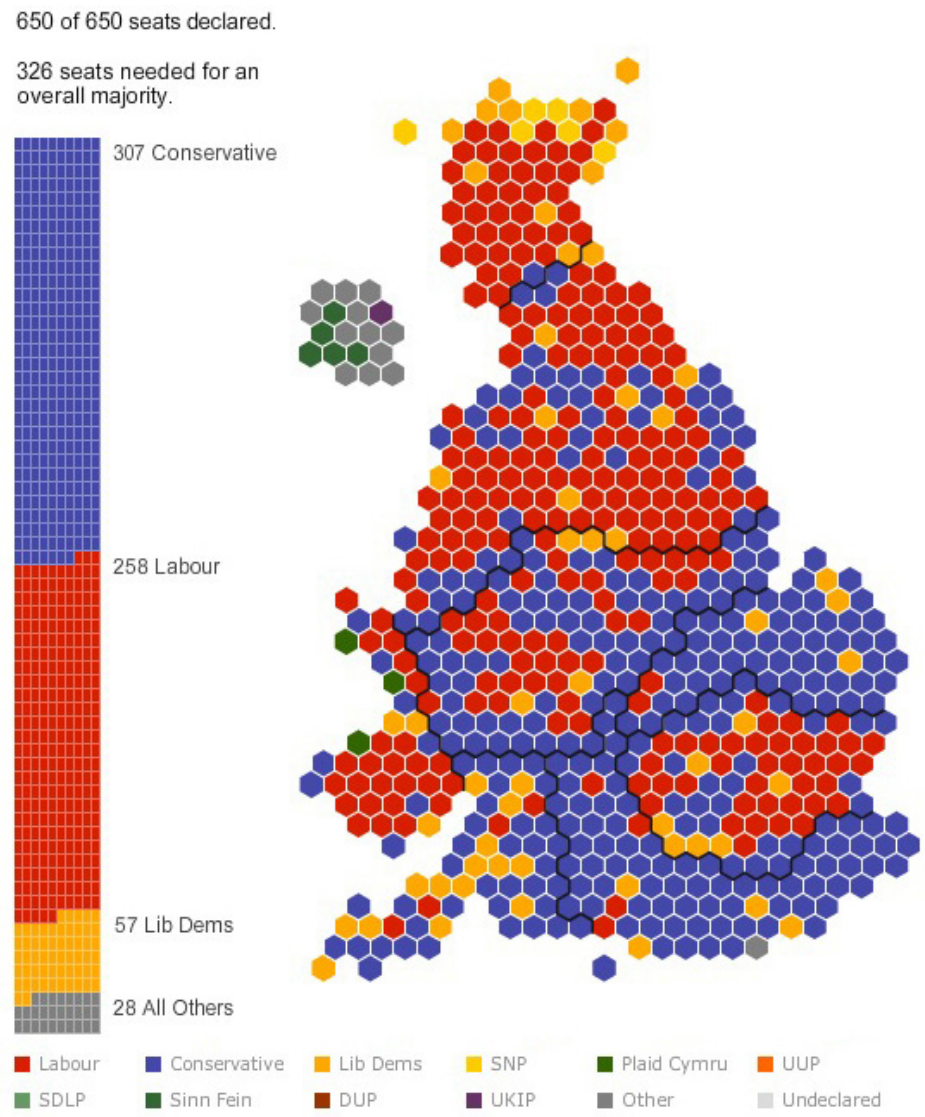

Fuente: news.bbc.co.uk (octubre de 2011)

\subsubsection{Organigramas}

Ordenan realidades intangibles, como el tiempo o las fases de un proceso, y jerarquizan conceptos o elementos figurados. Son ejemplos de este tipo los calendarios, los esquemas

\subsubsection{Diagramas}

A diferencia de los anteriores, éstos permiten describir realidades físicas de cualquier tipo, como construcciones, objetos, mecanismos, etc. y recrear o simplificar su interior o sus partes para ser explicadas de una forma que ningún otro tipo de imagen podría hacer. 


\subsubsection{Multigráficos o 'megagráficos'}

Aunque solemos denominar con el mismo nombre -infográfico tanto a una pequeña fiebre estadística como a una compleja ilustración a página completa, es obvio que sólo en este segundo caso nos encontramos con una pieza informativa propia e independiente. El megagráfico o multigráfico aborda en profundidad un tema desde su vertiente informativa y puede llegar a agotarlo e incluso a permitir prescindir de otros elementos textuales tradicionales. Se trata de auténticos reportajes visuales que elevan a este género hacia lo más sublime de su naturaleza. En estos megagráficos se utilizan todos los demás tipos de gráficos, como diagramas, tablas, mapas, etc. de forma coordinada para hilar una historia o explicación compleja. ${ }^{4}$

\subsection{Diferencia con la ilustración}

Aunque es cierto que muchos infográficos suelen incluir elementos ilustrativos en ocasiones atrayentes y potenciadores de una función casi estética, debemos diferenciarlos claramente de las ilustraciones ${ }^{5}$.

La ilustración es una interpretación alegórica o artística de un determinado tema tratado por un medio de comunicación. Sustitutas de la fotografía en aquellos casos en que ésta resulta menos pertinente o accesible, sirven para potenciar el diseño y aligerar la monotonía de una página cuya lectura, en caso de no incluirla, podría resultar pesada para el lector, más habituado hoy día a 'mirar' que a 'leer'. Tienen por tanto una función estética o de ornamentación del diseño del diario, que, además, las puede utilizar como elemento diferenciador frente a la competencia.

El infográfico, por contra, tiene como función principal la de comunicar una información o explicar una serie de acontecimientos o datos que, de otra forma, serían mucho más difícilmente transmisibles y, sólo de manera secundaria, atraer la atención del lector con elementos estéticos o artísticos. Anteponer dicha función atrayente o decoradora de datos a la realmente informativa sólo conduce a crear híbridos, productos mixtos sin personalidad propia ni apariencia de género propio y que acaban por no cumplir realmente ninguna de esas dos pretensiones, por lo que acaban siendo difícilmente aceptables por un lector que hoy ya sí es capaz de darse cuenta de que tras dicha mixtura no hay sino un despropósito.

\subsection{El "boom" de la infografía de prensa}

La aparición de los ordenadores y las aplicaciones informáticas de dibujo vectorial y tratamiento fotográfico ${ }^{6}$ a partir de los años 80 facilitaron la creación de infográficos. Además, la especial situación que vivió la prensa en 1991, durante la Guerra del Golfo, en la que la información gráfica fue fuertemente censurada (SERRA, 1998: 5 y GARCÍA, Mario, 1998: 1) provocó que se disparase la necesidad de este tipo de piezas informativas para sustituir a las fotos ${ }^{7}$. La doctrina es pacífica al datar en ese año el momento del estallido a nivel mundial de este tipo de productos en la prensa. Así, desde comienzos de los años 90 se han ido multiplicando en las páginas de los 
periódicos impresos hasta ser hoy un contenido habitual en ellos e irrenunciable para el lector.

\subsection{Partes del infográfico}

Por su naturaleza heterogénea y la disparidad de objetivos comunicativos para la que son utilizados los infográficos pueden presentarse en muy diferentes formatos, con apariencias dispares y formado por elementos constitutivos de muchos tipos. En ocasiones, ni siquiera la tradicionalmente básica descripción como 'imagen más texto' es básica, pues llegan incluso a darse casos extremos de infográficos creados exclusivamente por alguno de esos dos elementos. Aún así, atendiendo al arquetipo de gráfico periodístico es posible encontrar unos elementos comunes a prácticamente todos ellos y que son los siguientes.

\subsubsection{Titular y encabezados}

Todo infográfico ha de ser tratado como una unidad de lectura con significado propio. Así lo demuestra el hecho de que sea necesario que vayan antecedidos por un titular que resuma su contenido y, si es necesario, un subtítulo que redondee la explicación. Las diferentes partes que lo compongan también deberán disponer de su propio encabezamiento.

\subsubsection{Orden de lectura}

El orden de visualización es otro elemento esencial del infográfico, ya que a diferencia del texto, cuyo orden de lectura es inalterable, en el caso de los gráficos no es tan previsible que el lector vaya a explorarlos siguiendo un único sentido. Por ello, a la hora de plantear un infográfico debemos ser conscientes de que cada lector lo visualizará y explorará en un determinado orden o abandonará su lectura en un punto diferente. Esto obliga a redactarlos cuidadosamente y evitar la concatenación de afirmaciones textuales que dependan entre sí para poder ser comprendidas. Partiendo del elemento más destacado del gráfico, el lector podrá explorar el camino guiado por el autor o dejarse llevar por el peso visual relativo de las diferentes partes.

$\mathrm{Si}$, por el contrario, necesitamos que el orden de lectura sea respetado para que se comprenda la explicación contenida del infográfico, deberemos utilizar una numeración u ordenación explícita mediante viñetas, flechas o números, etc. que en nuestra lectura occidental habrá de llevarse a cabo siempre que sea posible de izquierda a derecha y en orden descendente.

\subsubsection{Elemento gráfico principal}

La dirección que tomen los ojos de lector al afrontar la lectura del infográfico vendrá condicionada por la presencia relativa y el peso visual de su elemento gráfico principal. Ya sea por su tamaño destacado o por su contraste cromático, es aconsejable que uno de los elementos destaque sobre el conjunto. Su visión suele ser 
incluso anterior a la lectura del propio titular del gráfico, por ello, dicho elemento ha de cumplir dos funciones importantes: la de anunciar el tema en torno al que gira la escena -y a cuya lectura sirve como punto de partida - y la de ordenar en torno a sí al resto de informaciones o gráficos subordinados tanto jerárquica como visualmente. Por ello, una buena elección de este elemento gráfico principal resulta crucial a la hora de concebir la pieza.

\subsubsection{La red o 'malla'}

El contexto gráfico necesario para comprender las proporciones internas y la ubicación de las informaciones se denomina malla o red (BARNHURST, 1999:4). Se trata de una definición abstracta de todos aquellos elementos visuales en los que se apoya el infografista para conseguir que el infográfico disponga de un entorno coherente en el que situar el resto de los elementos - estos ya sí, informativos-y que éstos sean más fácilmente comprensibles. Por ejemplo, la malla de un gráfico estadístico estaría compuesta por la matriz cartesiana en la que suelen apoyarse los datos. La de un mapa vendría a ser la escala proporcional o la proyección cartográfica utilizadas. En la representación de una escena, ésta sería el tipo de perspectiva utilizado -que puede ser axonométrica o cónica-.

\subsection{5, Fuentes, referencias y créditos}

Otro elemento obligatorio en todo infográfico es la mención de la fuente de la información utilizada, así como la firma o créditos indicadores de la autoría del mismo. Éstos seguirán criterios similares a los del resto de piezas escritas en el diario. Así, si necesitan ganar verosimilitud por tratarse de afirmaciones subjetivas o discutibles deberán atribuirse a fuentes, $y$, en el caso de se estime pertinente para su comparación o resulte interesante que el propio lector los amplíe se deberá citar la referencia.

\subsection{La estaticidad}

Todo lo descrito hasta aquí responde a un entorno bidimensional, es decir, las dos limitaciones principales de todo infográfico concebido para ser imprimido sobre el papel. El lector que lo recorre con sus ojos sabe que esas imágenes impresas no van a moverse ni a cambiar en el tiempo, ni mucho menos a responder a sus gestos o interactuar con él. Sabemos que los infográficos impresos son estáticos por naturaleza. El soporte papel obliga al infografista a concebir gráficos que desde el primer vistazo se muestran por completo al lector y que después éste procederá a su lectura en el orden que crea oportuno. Por ello es labor del infografista adelantarse a los posibles movimientos de su lector y disponer la información de tal manera que fluya con naturalidad cuando el público proceda a su visionado.

¿Pero qué ocurre cuando los acontecimientos o procesos que se describen en el infográfico ocurren en fases sucesivas o relatan sucesos temporales que necesariamente han de ser leídos en un orden concreto para poder ser comprendidos correctamente? En esos casos el infografista se ve obligado a utilizar viñetas, flechas y 
elementos iconográficos, numeraciones, etc. para que el lector no se pierda y el gráfico sea seguido y decodificado ordenadamente. En el caso de la cultura occidental, por ejemplo, convendrá respetar un orden de lectura de izquierda a derecha y de arriba abajo. El resto de criterios de ordenación y jerarquización de las escenas coincide con aquellos otros utilizados en la narrativa secuencial impresa utilizada, por ejemplo, en el cómic.

En resumen; el infográfico impreso ofrece la gran ventaja de la visualización unitaria y global, ya que de un golpe de vista el lector tiene ante sí una información que primero observa en conjunto y a continuación, si lo desea, explorará libremente para decodificarlo, descubrirlo y disfrutarlo durante todo el tiempo que quiera. Pero, por otro lado, el infográfico impreso cuenta también con la mencionada limitación derivada de su estaticidad; lo que obliga al autor a agudizar el ingenio a la hora de plasmar la temporalidad, la secuencialidad de aquellos acontecimientos o procesos que discurren a lo largo del tiempo. Con los gráficos audiovisuales ocurre lo contrario.

\subsection{Los infográficos audiovisuales}

Denominamos así a aquellos gráficos que en lugar de ser visionados sobre el papel o cualquier otro soporte impreso son reproducidos mediante un televisor, monitor de ordenador o en cualquier tipo de dispositivo dotado de reproducibilidad sobre una pantalla, como tablets, teléfonos, etc. Además, en la mayoría de las ocasiones son susceptibles de ir acompañados de audio; documentos sonoros, etc. El Periodismo utiliza este tipo de infográficos en los informativos, los documentales, etc., pero también podemos encontrarlos en la Publicidad, los museos, los paneles informativos electrónicos de cualquier tipo, etc.

La principal característica diferenciadora de este tipo de gráficos es la inclusión de una nueva dimensión; el factor tiempo. Este aspecto revoluciona por completo su naturaleza, ya que permite al infografista ofrecer la información con unos recursos similares a los disponibles en los gráficos impresos, pero a los que, además, se añaden las posibilidades que ofrece el discurso audiovisual, ya que se mueven, discurren y suceden sobre un espacio móvil. El infográfico audiovisual, por tanto, está vivo ante los ojos del espectador. Permite una disposición sucesiva de lo contado, pero, por contra, su mensaje tiene también las limitaciones propias de la narrativa audiovisual; ya que se produce siempre de forma unidireccional, dependiente de la duración y parcial respecto a la globalidad del mensaje

\subsubsection{Lectura unidireccional}

A diferencia de los impresos, los infográficos audiovisuales no necesitan preocuparse de si el espectador los leerá en un orden u otro. Sencillamente, sus contenidos ya suceden y se ordenan en esa dimensión inflexible que es el tiempo, así que el espectador no podrá equivocar qué sucede antes y qué después. Pero por esa misma razón, ese espectador no tiene aquí ya la posibilidad de elegir en qué orden explorar 
el gráfico, ya que éste ocurre ante sus ojos para que sea consumido de una forma más pasiva que el infográfico impreso.

\subsubsection{Dependencia de la duración}

Mientras que sobre el papel cada lector concreto puede necesitar una determinada cantidad de tiempo diferente para comprender las explicaciones o las diferentes partes del infográfico o saciar sus necesidades informativas seleccionando aquellas zonas que pudieran interesarle en exclusiva, el infográfico audiovisual, por contra, es visionado por todos sus espectadores en el mismo lapso de tiempo. Así, el gráfico debe contar con que es posible que el espectador no pueda volver hacia atrás durante el visionado de esa explicación del hundimiento del Titanic, o el esquema de juego del Manchester United o las instrucciones de seguridad del avión en que viaja si no ha entendido correctamente determinada información o si, al contrario, le ha gustado mucho una parte concreta, o sencillamente no ha podido escucharla o, sencillamente, se ha perdido el comienzo. Además, la comprensibilidad del infográfico en su conjunto o su sentido puede verse alterado por los diferentes ritmos de lectura con los que cada espectador concreto alcanza a comprender o preferiría consumirlo, o, sencillamente, le ha sido posible atender.

Por todo ello, los infográficos diseñados para la pantalla se ven constreñidos a utilizar datos e imágenes lo más sencillas posibles. La información a ser comunicada debe ser concisa, ya que sólo será visualizada durante un lapso de tiempo determinado. A veces podrán ser acompañadas de sonido -audio o voz en segundo plano- para aclarar o repetir su contenido.

\subsubsection{Lectura continua y por tanto parcial}

Desde el primer momento en que afrontábamos la lectura de un infográfico impreso teníamos una visión de conjunto del mismo. Sabemos qué espacio total ocupa el mensaje global y el peso relativo de sus partes y es a continuación cuando pasamos a explorarlo o a decodificar sus partes sin perder esa visión global. En la narrativa audiovisual, por el contrario, el espectador está inmerso en una historia necesariamente secuencial y es precisamente esa inmersión la que imposibilita obtener la perspectiva global del mensaje hasta que no finaliza su reproducción. Ello también posibilita utilizar el factor sorpresa u otros recursos comunicativos no predecibles de antemano para mantener la atención del espectador, ya que en la narrativa audiovisual en general éste se encuentra en esa situación de incertidumbre constante y controlada.

\subsection{El gráfico interactivo}

Al igual que la infografía audiovisual, también la interactiva tiene como soporte de reproducción el monitor del ordenador o la pantalla de cualquier otro tipo de dispositivo tecnológico pero en este tercer tipo de gráficos el usuario puede interactuar de algún modo con el interfaz de reproducción de éstos. El nivel de interactividad puede ir desde la operación más sencilla, como poder pausar dicha reproducción o 
retroceder y avanzar a lo largo de ella (el simple botón play/pause en el monitor de un museo), hasta la mayor complejidad de los infográficos pensados para ser reproducidos a través de navegadores web e interfaces digitales con posibilidad de entrada de datos. Como ejemplo de una interactividad alta valga el infográfico publicado en 2010 por The New York Times en su web. Mediante él lo lectores podían comprobar si les salía más rentable comprar su casa o alquilarla, atendiendo a su propia situación económica y personal. Tras introducir sus datos económicos y sus perspectivas futuras, el resultado gráfico aconsejaba una u otra opción para cada lector. Ante este tipo de infográficos el usuario alcanza una mayor libertad de movimientos al tener capacidad de navegación por los contenidos. Gracias a ello, el infográfico interactivo se libera también de las tres limitaciones comentadas más arriba para los audiovisuales, ya que:

\subsubsection{Es multidireccional}

El usuario puede en cualquier momento retroceder o avanzar a lo largo de múltiples direcciones en el gráfico. Ello obliga también al infografista a concebir un método de navegación que resulte intuitiva para el mayor número posible de usuarios potenciales. Igualmente, deberá prever un orden de lectura con múltiples posibilidades. Dado que en ocasiones el usuario saltará desordenadamente de unas partes a otras del gráfico -que ya no podemos considerar por tanto como fases necesariamente sucesivas- el infografista habrá de preocuparse por que el usuario: 1.- No se pierda al pasar por cada una de ellas, y 2.- Pueda entender el gráfico en su conjunto incluso aunque desordene dicha lectura.

\subsubsection{Es independiente respecto del factor tiempo}

Desde el momento en que el propio usuario es libre de decidir a qué aspectos del gráfico dedicar más atención y observar pausadamente o cuáles otros saltar sin detenerse a leer, el infografista puede por fin despreocuparse de esta limitación. Allí donde sea necesario podrá incluir toda la información que desee -tanto textual como iconográfica- sabiendo que cada lector adaptará el ritmo de lectura a su gusto o capacidades. El infográfico interactivo ofrece las mismas posibilidades que el impreso en ese aspecto.

\subsubsection{Da una visión de conjunto o primera lectura general}

El infográfico interactivo está vivo. Si el infografista así lo quiere, puede hacer que desde el primer vistazo el lector sepa cuál será el tamaño o duración relativa que tendrá todo él o cada una de las partes que lo componen y poder sentirse ubicado continuamente. De hecho, uno de los elementos de que debe disponer todo infográfico interactivo es un interfaz de navegación que servirá no sólo para moverse ágilmente entre todas sus zonas, sino que además, como si de un mapa aéreo se tratase, nos ubique continuamente para que no perdamos la noción de qué importancia relativa, peso, situación y presencia tiene cada una de esas partes dentro del contexto global. 


\section{Conclusión}

Haciendo honor a su lema Show, don't tell, los infográficos se han convertido en una pieza más en los medios de comunicación actuales y pueden ser analizados y diseccionados como los demás géneros informativos tradicionales.

Atendiendo a su estaticidad (impresos), linealidad (audiovisuales) e interactividad (digitales) cada uno de los tres tipos de gráficos es una herramienta de comunicación diferente, que aporta capacidades informativas diversas y que adolece de sus propias restricciones derivadas principalmente de esos tres tipos de naturaleza claramente diferenciados y en los que, como se ha visto, el factor 'tiempo' e 'interactividad' es la principal clave para entender las potencialidades de cada uno.

\section{Bibliografía}

ABREU SOJO, Carlos (2000): La infografía periodística. Fondo editorial de Humanidades y Educación. Univ. Central de Venezuela, Caracas.

BARNHURST, Kevin G. (1999): La diagramación de noticias. Revista Latina de Comunicación Social, 14.

BORRAS, Leticia (2000): Infototal, inforrelato e infopincel. Revista Latina de Comunicación Social, 35. Extra Argentina

CAIRO, Alberto (2008): Infografía 2.0. Alamut. Madrid

COLLE, Raymond. Estilos o tipos de infógrafos. Revista Latina de Comunicación Social, 12. Diciembre de 1998.

DE PABLOS (1998): Infoperiodismo. El periodista como creador de infografía. Ed. Síntesis. Madrid

GARCÍA, Mario R. (1998): Tendencias en comunicación periodística visual. Revista Latina de Comunicación Social, 3.

GOÑI ALFARO, Óscar (1998): El grafismo en un diario regional. Revista Latina de Com. Social, 10.

LARRONDO URETA, Ainara (2008). Los géneros en la redacción ciberperiodística. UPV/EHU. Leioa

LESTER, Paul Martin (2000): Visual Communication. Wadsworth. Thomson Learning. Nueva York. (2006): Visual Communication: Images with Messages. Wadsworth. Thomson Learning. Belmont. EE UU.

PELTZER, Gonzalo (1991): Periodismo iconográfico. Ediciones Rialp. Madrid.

SERRA, Josep M. (1998): La irrupción del infografismo en España. Revista Latina de Com. Social, 11.

TUFTE, Edward (2001): The Visual Display of Quantitative Information. 2a. ed Graphic Press. Connecticut 


\section{Notas}

1 DE PABLOS (1998: 3) se decanta por atribuir a la presencia del binomio 'texto+imagen' la existencia de infográficos, mientras otros autores (por todos, CAIRO, 2008: 21) nos recuerdan como es perfectamente posible crear infográficos sin presencia alguna de texto.

2 Aunque Peter SULLIVAN considera el publicado en 1740 por el 'Daily Post' como el primer gráfico de la historia -en él se explica el ataque del almirante Vernon contra la ciudad de Portobello-, es otro posterior, de 1806 -en el que el londinense 'The Times' narra mediante la reproducción de una escena el asesinato de un ciudadano y el recorrido seguido por el asesino- al que suele atribuirse el hito de ser el primero propiamente concebido y elaborado desde criterios periodísticos para ser leído por el público habitual de un medio masivo.

3 Para una clasificación exhaustiva de los tipos de infográficos, ver: PELTZER (1991: 130-133), LETURIA (1998: 3-4), BARNHURST $(1999,4)$ y CAIRO (2008)

4 Véanse otros gráficos de "difícil clasificación” LESTER (2006: 194)

5 Leticia BORRÁS (2000: 4) y Óscar GOÑI (1998: 10) nos insisten en que las imágenes que integran los infográficos han de cumplir principalmente una función informativa. Y el gurú de la visualización de datos Edward TUFTE llegará a establecer junto a sus famosos cinco principios de excelencia infográfica (2001: 77) la ratio 'Data/Ink', es decir, información transmitida partido por tinta utilizada.

6 Los más utilizados en las redacciones han sido tradicionalmente los de dibujo vectorial -Aldus Freehand (después Macromedia Freehand) y Adobe Ilustrator-y de retoque de imágenes (Adobe Photoshop).

7 VALERO SANCHO (2002: 6) llega a afirmar que la presencia sólo de gráficos respecto de un determinado evento relevante puede incluso ser la pista de que éste no ha podido ser cubierto por fotógrafos.

\section{El autor}

Daniel García González es profesor en el Departamento de Periodismo II de la Facultad de Ciencias Sociales y de la Comunicación de la Universidad del País Vasco / Euskal Herriko Unibertsitatea. Licenciado en Periodismo por la UPV/EHU y en Derecho por la Universidad de Deusto, imparte en castellano y euskera las asignaturas de Empresa Informativa, Principios del Diseño Periodístico y Tecnología del Periodismo, así como, en inglés, Infografía -Infographics-. Se doctoró en enero de 2012 con la tesis titulada Evolución de la infografía periodística en España. El caso de El Correo Español-El Pueblo Vasco. 